\title{
НАБЛЮДЕНИЕ ПОДРОСТКОВ С НАРУШЕНИЕМ ФОРМИРОВАНИЯ ПОЛА, ОБУСЛОВЛЕННЫМ Ү-ПОЗИТИВНЫМ ГОНОСОМНЫМ МОЗАИЦИЗМОМ
}

\author{
Райгородская Н.Ю., Болотова Н.В., Черных В.Б, Морозов Д.А., Опарина Н.В., Корнеева К.А.
}

Фенотипическая вариабельность Ү-позитивного гоносомного мозаицизма обусловливает отсутствие единой тактики выбора пола, наблюдения и лечения пациентов. Цель: оценить физическое, соматическое и половое развитие подростков с НФП, обусловленным мозаицизмом по Y-хромосоме.

Материалы и методы: проведена динамическая оценка соматического и полового развития 7 неродственных пациентов в возрасте 12 - 15 лет с различными вариантами Y-позитивного гоносомного мозаицизма. Возраст на момент постановки диагноза варьировал от 3 мес до 12 лет.

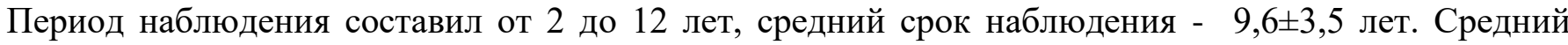

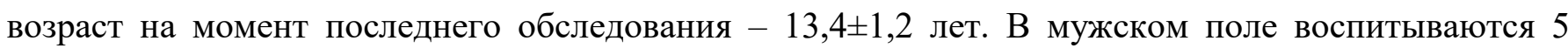
пациентов, в женском - 2 пациентки, в том числе у одной выполнена смена пола в возрасте 4 лет. Проведены изучение анамнеза, осмотр, оценка физического и полового развития, УЗИ гонад и внутренних гениталий; определение гонадотропных и половых гормонов в сыворотке крови: ЛГ, ФСГ, тестостерона, эстрадиола; онкомаркеров герминативных опухолей: АФП, бета-ХГЧ, ЛДГ.

Результаты: По данным анамнеза двойственное строение наружных половых органов при рождении имели 6 из 7 детей, феминный фенотип - 1 пациентка. Хирургическая коррекция наружных гениталий в соответствии с выбранным полом выполнена детям в возрасте от 1,5 до 4,5 лет $(3,1 \pm 1$ года). При первичном обследовании дисгенетичные гонады обнаружены у 5 детей, выполнена гонадэктомия; овотестикулярные гонады - у одного ребенка, имевшего SRY++ мозаицизм 46,XX/47,XX,idic(Y)(p11.2), выполнена сепарация гонад с сохранением овариального компонента; тестикулы в паховых каналах - у одного пациента, проведена орхиопексия. Производные Мюллеровых протоков различной степени развития были обнаружены у 6 пациентов, в том числе у 4 пациентов мужского пола (удалены) и у 2 пациенток женского пола (сохранены).

При обследовании в возрасте 11 - 12 лет отмечена задержка роста (SDS - 2,4 40,7$)$, установленная у 5 из 7 (67\%) детей, в сочетании с нарушением пропорций тела и укорочением нижнего сегмента тела у 3 (43\%) мозаиков. Костный возраст соответствовал паспортному - 5, опережал паспортный возраст на 1 - 1,5 года у двоих. Аномалии строения аортального клапана диагностированы у 3 (43\%) пациентов, пороки развития почек - у 2 (28\%) пациентов. Самостоятельная инициация пубертата зафиксирована у 4 (57\%) пациентов, трое детей (57\%) не имели признаков самостоятельного пубертата в результате отсутствия $(\mathrm{n}=1)$ либо гипотрофии $(\mathrm{n}=2)$ гонад. Наиболее ранним проявлением функциональной недостаточности гонад являлось повышение уровня ФСГ у $6(86 \%)$ пациентов в возрасте 11,3 $\pm 0,4$ лет. Повышение концентрации ЛГ определено у двоих, допубертатные показатели ЛГ и половых гормонов - у 2, пубертатные показатели ЛГ и половых стероидов - у 3 пациентов. По результатам УЗИ и определения онкомаркеров крови, герминативные опухоли не диагностированы.

Выводы: 1) Для пациентов с НФП, связанным с мозаицизмом по Y-хромосоме, характерна задержка роста (67\%) в сочетании с диспропорциональным развитием (43\%) и отсутствие признаков самостоятельного пубертата (43\%); врожденные аномалии развития. 2) Наиболее ранним проявлением функциональной недостаточности половых желез являлось повышение уровня ФСГ в возрасте 11,3 $\pm 0,4$ лет. 3) комплексное динамическое наблюдение пациентов с НФП, обусловленным гоносомным мозаицизмом, необходимо для своевременного выявления патологии соматического и полового развития. 